MIDPI

MOL2NET, International Conference Series on Multidisciplinary Sciences http://sciforum.net/conference/mol2net-03

sciforum

\title{
MOLECULAR MODELING OF NUCLEOTIDE DERIVATIVES OF 2,5- DIHYDROFURAN-2,5-DIOL FOR EVALUATION OF POTENTIAL ANTITUBERCULAR ACTIVITY
}

Alex France Messias Monteiro ${ }^{\mathrm{a}}$, Marcus Tullius Scotti ${ }^{\mathrm{a}}$, Luciana Scotti ${ }^{\mathrm{a}, \mathrm{b}}$

${ }^{a}$ Federal University of Paraíba, Health Sci. Center, 50670-910, João Pessoa, PB, Brazil;

${ }^{b}$ Teaching and Research Management - University Hospital, Federal University of Paraíba, João

Pessoa, PB, Brazil;

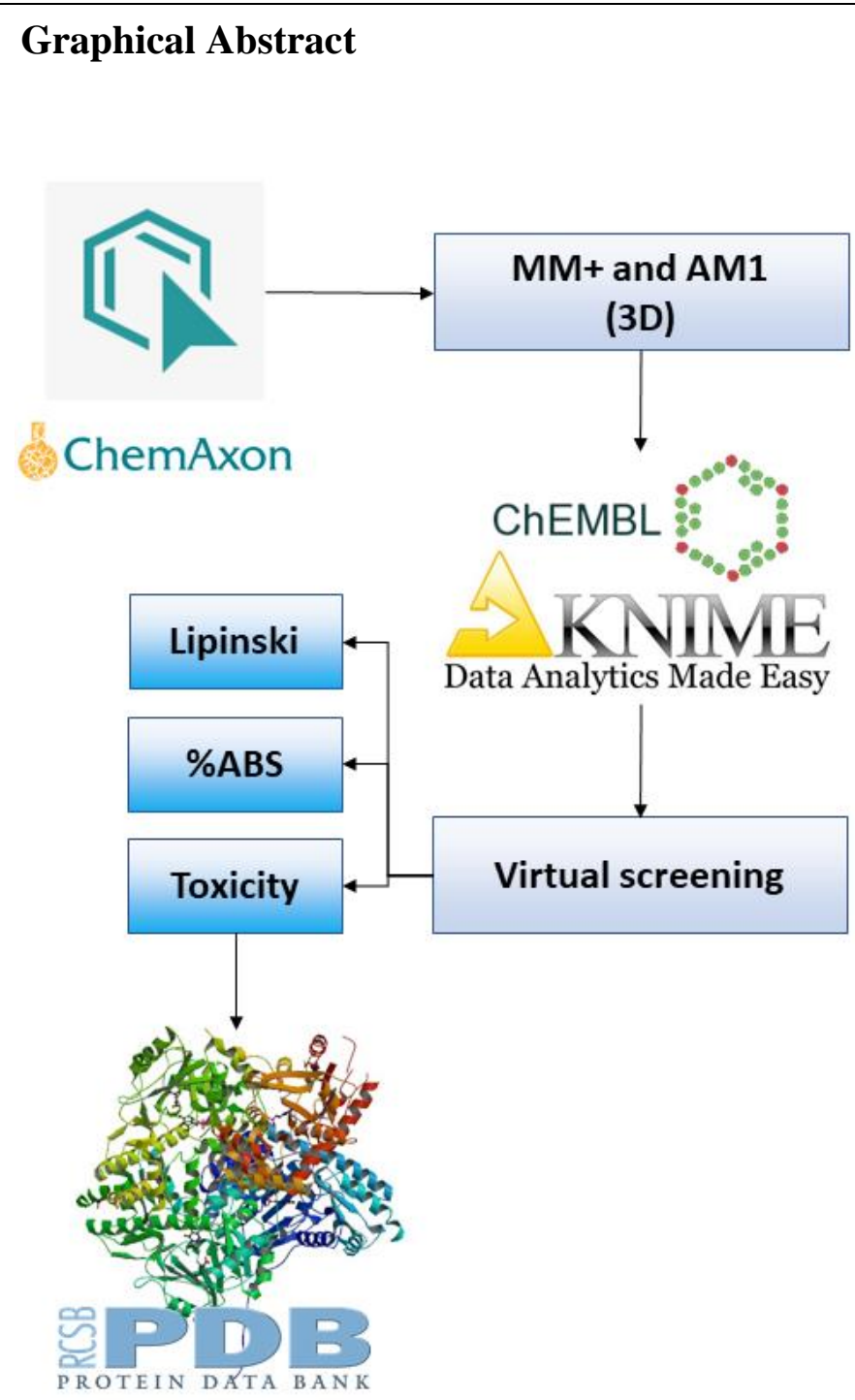

Abstract.

Tuberculosis is a disease caused by bacterial infection, which mainly compromises the respiratory system leading to death if left untreated. Currently the treatment is efficient, although bacterial resistance has been hindering and even prevented the progress of treatment for many patients. The transmission medium should be in several areas or direct contact with contaminated body fluids. Many therapeutic targets are addressed in research involving rational planning of new drugs with antitubercular activity, always in search of more efficient bioactive and with increasingly reduced toxicity. Thus, this work consists of an in silico proposition through the molecular modeling of nucleotide compounds against tuberculosis. For the development of this research were used chemoinformatics tools for structural design, optimization, virtual screening taking into account Lipinski rule, absorption rate and cytotoxicity risks. Finally, a molecular docking study was conducted to know the existing ligandreceptor interactions and to compare them with those of the drugs used as controls for this research. Finally, it is possible to perceive the existence of promising molecules for the antitubercular activity of synthetic nucleosides. 


\section{Introduction}

The bacteria Mycobacterium tuberculosis is responsible for the pathology known as tuberculosis, which is one of the top 10 causes of death in the world, according to the World Health Organization (WHO) in 2017 about 10 million people contracted the disease, of which 1.6 million died last year. The bacterial infection in its primary form compromises the lungs, however, it is possible to reach the brain, bones, heart, kidneys and other organ of the human body. The form of transmission is mainly through the air, where infected people cough, sneeze or spit spreading the bacteria, leaving it available to contaminate new individuals. $\left[{ }^{1},{ }^{2},{ }^{3},{ }^{4}\right]$

Tuberculosis is treatable with the aid of antibiotics and avoided from childhood with the aid of the vaccine BCG (Bacillus Calmette-Guérin), however, studies show that $82 \%$ of tuberculosis cases the bacterium develops resistance to first-line drugs such as rifampicin, due to this problem, research in the field of pharmaceutical sciences is necessary to make new bioactive available to treat the disease. Some authors have developed studies on the use of nucleoside / nucleotide analogues as antitubercular bioactive and have shown good results that have made this class of synthetic compounds promising drug candidates in the fight against $M$. tuberculosis. $\left[{ }^{5},{ }^{6},{ }^{7}\right]$

Knowing the potential activity against tuberculosis of nucleotides, the objective of this study is the molecular modeling with the use of several computational tools for the theoretical proposition of some derivatives of 2,5-dihidroxyfuran-2,5-diol with adenine against tuberculosis-causing bacteria. For the initial part of this research, a model of activity prediction was developed in the KNIME, thus, nucleotides that were active against the model were subjected to a virtual screening and molecular docking, as well as the drugs used as controls: pyrazinamide, ethambutol, rifabutin, amikacin, levofloxacin, ethionamide and protionamide.

\section{Materials and Methods}

The nucleotide molecules together with the drugs used as controls were designed using the software Marvin Sketch 18.21 $\left[^{8}{ }^{9}{ }^{9}\right]$ of ChemAxon $\odot$ to obtain their 2D structures, then they were imported into the software HyperChemTM (RMS $0.1 \mathrm{kcal}^{\mathrm{mol}} \mathrm{m}^{-1} . \AA^{-1}$ in 600 cycles) $\left[{ }^{10},{ }^{11}\right]$ to obtain their structures in $3 \mathrm{D}$ and, optimization through the methods of molecular and semi-empirical mechanics. $[12,13,14]$

These molecules were submitted to a classificatory model of prediction of activity developed in the KNIME Analytics Platform $3.7\left[{ }^{15},{ }^{16}\right]$ (https://doi.org/10.6084/m9.figshare.7445666.v2) in which it was used for its creation the molecules of the database of chemical structures ChEMBL (https://www.ebi.ac.uk/chembl) $\left[{ }^{17},{ }^{18}\right]$, as well as the descriptors generated in the software CDK Descriptor Calculator 1.4.8 (http://www.rguha.net/code/java/cdkdesc.html). $\left[{ }^{19},{ }^{20}\right]$

The molecules approved in the prediction model were subjected to a continuous virtual screening of the series of compounds studied, thus, the molecules were imported into the software OSIRIS DataWarrior 4.7.3 (http://www.openmolecules.org) $\left[{ }^{21},{ }^{21}\right]$ to analyze cytotoxicity risks in four parameters (mutagenicity, carcinogenicity, irritability in the skin and effect on the reproductive system), considering only the molecules that presented no risk in any of the presented parameters.

Following the virtual screening of the non-toxic molecules, Lipinski's rule and absorption rate $(\%$ ABS $=109-0.345 *$ TPSA $)\left[{ }^{22},{ }^{23}\right]$, being considered the derivatives that presented oral absorption rate greater than the lowest rate among the controls used and at most a violation of the Lipinski rule. 
Finally, the molecules approved in the virtual screening were submitted to molecular docking with the software Molegro Virtual Docker 6.0 (MVD) $\left[{ }^{24},{ }^{25}\right]$ using the crystalline proteins of Mycobacterium tuberculosis PDB ID 5VRN corresponding to InhA with $2.55 \AA$ of resolution, and protein PDB ID $5 \mathrm{YHV}$ corresponding aminotransferase with $2,7 \AA$, both with the respective inhibitors complexed together with the protein.

\section{Results and Discussion}

25 nucleotide analogs were submitted to the model of prediction of biological activity, all of which presented activity according to the model that presented ROC curve of 0.913 , accuracy of 0.813 and Matthews coefficient equal to 0.627 , with these statistical data it is possible to perceive that the model created showed good predictability of the molecules tested, it is worth noting that all the structures presented within the applicability domain of the model, guaranteeing the reliability of the results of the classifying model of antitubercular prediction.

According to the prediction of cytotoxicity risks performed for the 25 molecules that present activity against the model, none presented risks in any of the four parameters analyzed by OSIRIS. Considering Lipinski's rule as a virtual screening parameter, the molecules, seven molecules analyzed had two violations, so, with the others, the oral absorption rate (\% ABS) was calculated, all of which presented a higher rate than the lowest rate among the controls (amikacin - \%ABS = -5.52).

\section{Molecular Docking}

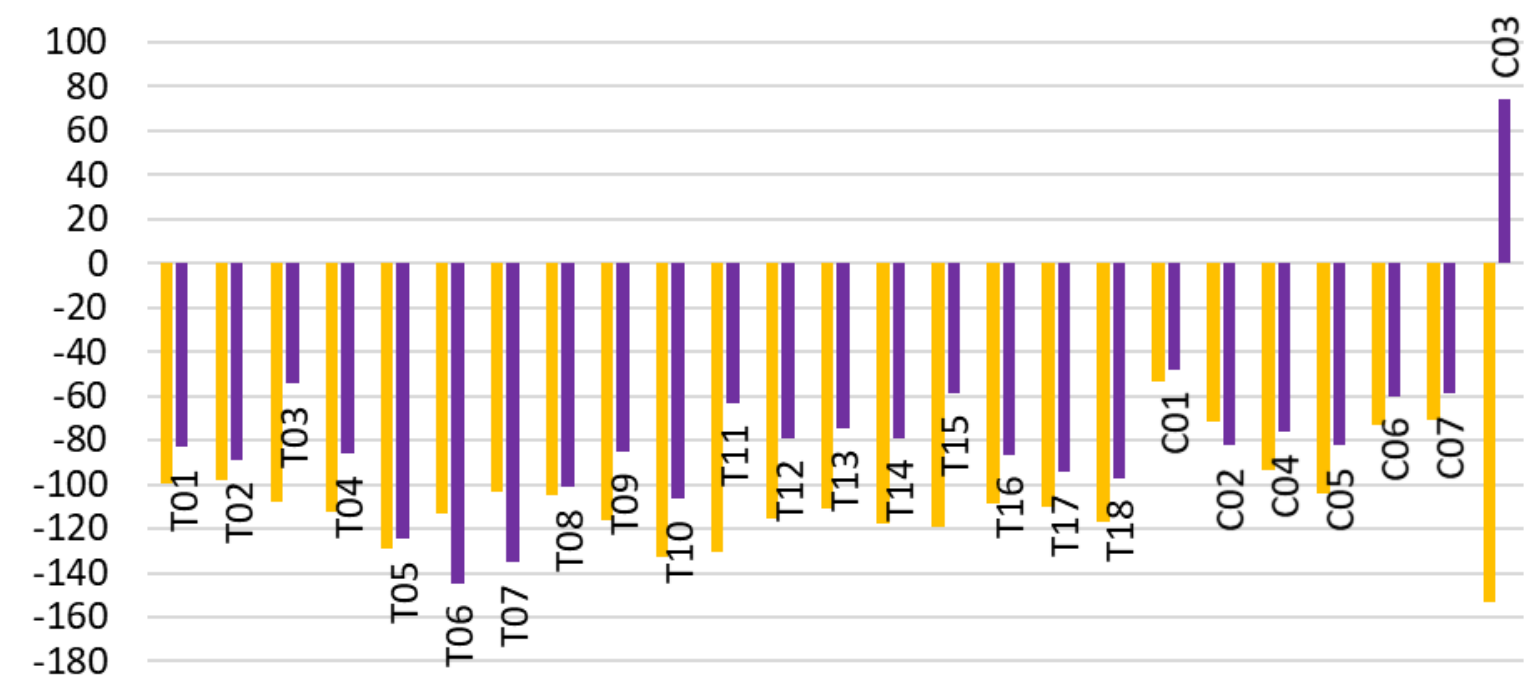

Figure 1. Molecular docking energies [ $\left.\mathrm{kcal}_{\mathrm{mol}}{ }^{-1}\right]$. Orange column corresponds to protein PDB ID 5VRN and purple column corresponds to protein PDB ID 5 YHV.

With the results already reported, the 18 compounds used were subjected to molecular docking with the proteins of M. tuberculosis together with the controls, for the PDB ID 5VRN protein the energies ranged from $-53.2479 \mathrm{kcal}^{\mathrm{mol}}{ }^{-1}$ to $-153.401 \mathrm{kcal}^{\mathrm{mol}}{ }^{-1}$, to protein PDB ID 5YHV is $74.3982 \mathrm{kcal}^{\mathrm{mol}}{ }^{-}$ ${ }^{1}$ to $-144.5640 \mathrm{kcal}^{\mathrm{mol}}{ }^{-1}$.

15 of the 18 derivatives presented better MolDockScore values than 6 of the 7 controls used, and the 18 compounds studied presented better molecular docking results than: C01, C02, C04, C06 and C07 
for the $5 \mathrm{VRN}$ protein. For the $5 \mathrm{YHV}$ protein, 12 of the 18 derivatives had better energy than the 7 controls and all presented better results than the $\mathrm{C} 01$ and $\mathrm{C} 03$, as shown in Figure 1.

\section{Conclusions}

Other studies are needed to propose a prototype to the antitubercular drug, however, this research is important to draw attention to the possibility of new bioactive drugs with action against tuberculosis. As this study it is possible to notice that of the series used in this work, 18 compounds presented better results than the 25 initially considered, which the molecules can be seen in the supplementary material.

\section{References}

[1] Doria, J. L.; Duarte, J. M. C.; Saraiva, P. C. S. Tuberculosis: History and Heritage. An. Inst. Hig. Med. Trop. (Lisb). 2017, 16, 89-101.

[2] Falzon, D.; Schünemann, H. J.; Harausz, E.; González-Angulo, L.; Lienhardt, C.; Jaramillo, E.; Weyer, K. World Health Organization Treatment Guidelines for Drug-Resistant Tuberculosis, 2016 Update. Eur. Respir. J. 2017, 49 (3), 1602308.

[3] Petruccioli, E.; Vanini, V.; Chiacchio, T.; Cuzzi, G.; Cirillo, D. M.; Palmieri, F.; Ippolito, G.; Goletti, D. Analytical Evaluation of QuantiFERON-Plus and QuantiFERON-Gold In-Tube Assays in Subjects with or without Tuberculosis. Tuberculosis 2017, 106, 38-43.

[4] Kumari, P.; Sikri, K.; Kaur, K.; Gupta, U. D.; Tyagi, J. S. Sustained Expression of DevR/DosR during Long-Term Hypoxic Culture of Mycobacterium Tuberculosis. Tuberculosis 2017, 106, 33-37.

[5] Walzl, G.; McNerney, R.; du Plessis, N.; Bates, M.; McHugh, T. D.; Chegou, N. N.; Zumla, A. Tuberculosis: Advances and Challenges in Development of New Diagnostics and Biomarkers. Lancet Infect. Dis. 2018, 18 (7), e199-e 210.

[6] Fletcher, H. A.; Chatterjee, M.; Cooper, A.; Hussell, T.; Kaye, P. M.; Prior, J.; Reljic, R.; Vermaak, S.; Vordermeier, M.; Williams, A. VALIDATE: Exploiting the Synergy between Complex Intracellular Pathogens to Expedite Vaccine Research and Development for Tuberculosis, Leishmaniasis, Melioidosis and Leprosy. F1000Research 2018, 7.

[7] Kaufmann, S. H. E.; Weiner 3rd, J.; Maertzdorf, J. Accelerating Tuberculosis Vaccine Trials with Diagnostic and Prognostic Biomarkers. Expert Rev. Vaccines 2017, 16 (8), 845-853.

[8] Costa, C. H. C.; Dantas Filho, F. F.; Moita, F. Marvinsketch e Kahoot Como Ferramentas No Ensino de Isomeria. Holos 2017, 1, 31-43.

[9] Neto, M. F. A. TRIAGEM VIRTUAL PARA A SELEÇÃO DE CANDIDATOS A INIBIDORES DA DIIDROOROTATO DESIDROGENASE DE PLASMODIUM FALCIPARUM. An. Semin. Iniciação Científica 2017, No. 21.

[10] Chan, T. I.; Ouyang, D. Investigating the Molecular Dissolution Process of Binary Solid Dispersions by Molecular Dynamics Simulations. Asian J. Pharm. Sci. 2018, 13 (3), 248-254.

[11] Di Scala, C.; Fantini, J. Hybrid in Silico/in Vitro Approaches for the Identification of Functional Cholesterol-Binding Domains in Membrane Proteins. In Cholesterol Homeostasis; Springer, 2017; pp 7-19.

[12] Heredia, A.; Gervacio-Arciniega, J. J.; Duarte-Alaniz, V.; Amelines-Sarria, O.; RodríguezGalván, A.; Siqueiros, J. M. Description of New Bioelectromechanical Properties in Alginate: An Insight with a Computer Simulation. Adv. Mater. Phys. Chem. 2017, 7 (08), 334.

[13] Pinheiro, P. de S. M.; Rodrigues, D. A.; Sant'Anna, C. M. R.; Fraga, C. A. M. Modeling Zincoxygen Coordination in Histone Deacetylase: A Comparison of Semiempirical Methods Performance. Int. J. Quantum Chem. 2018, 118 (21), e25720.

[14] Suzuki, Y.; Ida, T.; Endo, K.; Tadokoro, M.; Mizuno, M. Nanoscopic Structure of Hydrophilic and Hydrophobic Molecules in Artificial Clathrate Hydrates. J. Mol. Struct. 2018, 1170, 131140. 
[15] Leonis, G.; Melagraki, G.; Afantitis, A. Open Source Chemoinformatics Software Including KNIME Analytics. In Handbook of Computational Chemistry; Springer, 2017; pp 2201-2230.

[16] Landrum, G. Interactive and Reproducible Data Analysis with the Open-Source KNIME Analytics Platform. In ABSTRACTS OF PAPERS OF THE AMERICAN CHEMICAL SOCIETY; AMER CHEMICAL SOC 1155 16TH ST, NW, WASHINGTON, DC 20036 USA, 2018; Vol. 255.

[17] Mendez, D.; Gaulton, A.; Bento, A. P.; Chambers, J.; De Veij, M.; Félix, E.; Magariños, M. P.; Mosquera, J. F.; Mutowo, P.; Nowotka, M. ChEMBL: Towards Direct Deposition of Bioassay Data. Nucleic Acids Res. 2018, 1.

[18] Mayr, A.; Klambauer, G.; Unterthiner, T.; Steijaert, M.; Wegner, J. K.; Ceulemans, H.; Clevert, D.-A.; Hochreiter, S. Large-Scale Comparison of Machine Learning Methods for Drug Target Prediction on ChEMBL. Chem. Sci. 2018.

[19] de Sousa, J. M. A. Descriptors Generation Using the CDK Toolkit and Web Services. Tutorials in Chemoinformatics 2017, 127-134.

[20] Qiu, F.; Lei, Z.; Sumner, L. W. MetExpert: An Expert System to Enhance Gas Chromatographymass Spectrometry-Based Metabolite Identifications. Anal. Chim. Acta 2018.

[21) Tambunan, U. S. F.; Siregar, S.; Toepak, E. P. EBOLA VIRAL PROTEIN 24 (VP24) INHIBITOR DISCOVERY BY IN SILICO FRAGMENT-BASED DESIGN. Int. J. GEOMATE 2018, 15 (49), 59-64.

[22] Tuncbilek, M.; Kucukdumlu, A.; Guven, E. B.; Altiparmak, D.; Cetin-Atalay, R. Synthesis of Novel 6-Substituted Amino-9-( $\beta$-d-Ribofuranosyl) Purine Analogs and Their Bioactivities on Human Epithelial Cancer Cells. Bioorg. Med. Chem. Lett. 2018, 28 (3), 235-239.

[23] Reddy, P. O. V.; Hridhay, M.; Nikhil, K.; Khan, S.; Jha, P. N.; Shah, K.; Kumar, D. Synthesis and Investigations into the Anticancer and Antibacterial Activity Studies of $\beta$-Carboline Chalcones and Their Bromide Salts. Bioorg. Med. Chem. Lett. 2018, 28 (8), 1278-1282.

[24] Kusumaningrum, S.; Firdayani; Yanuar, A.; Arbianto, A. D.; Jannah, R. Virtual Screening of Natural HBV Capsid Assembly Inhibitor Using Molegro Virtual Docker for Identification of Potential Lead Compound for Hepatitis B. Res. J. Pharm. Biol. Chem. Sci. 2018, 9 (5), 14091416.

[25] Singh, L. K. S. M. B. QUANTITATIVE STRUCTURE ACTIVITY RELATIONSHIP AND MOLECULAR DOCKING STUDY OF DERIVATIVES CONTAINING 2AMINOBENZOTHIAZOLE AS ANTICONVULSANT AGENTS. Int. J. Innov. Eng. Res. Manag. ISSN 2348-4918, ISO 2000-9001 certified, E 2018, 5 (01). 